\title{
General Psychiatry Depression, suicidality and associated risk factors among police officers in urban Tanzania: a cross-sectional study
}

To cite: Njiro BJ, Ndumwa HP, Msenga CJ, et al. Depression, suicidality and associated risk factors among police officers in urban Tanzania: a cross-sectional study. General Psychiatry 2021;34:e100448. doi:10.1136/ gpsych-2020-100448

Received 22 November 2020 Accepted 18 May 2021

\section{Check for updates}

(C) Author(s) (or their employer(s)) 2021. Re-use permitted under CC BY-NC. No commercial re-use. See rights and permissions. Published by BMJ.

${ }^{1}$ School of Medicine, Muhimbil University of Health and Allied Sciences, Dar es Salaam, Tanzania, United Republic of ${ }^{2}$ Medical Unit, Tanzania Police Force, Dar es Salaam, Tanzania, United Republic of ${ }^{3}$ National NCD Prevention and Control Program, Ministry of Health, Community, Development, Gender, Elderly and Children, Dodoma, Tanzania, United Republic of

Correspondence to Dr Belinda Jackson Njiro; bellyjacky25@gmail.com

\section{ABSTRACT}

Background The WHO has classified depression as a disease of public concern. Police officers are a particular subpopulation group that is at an increased risk for mental health problems. This study examined the prevalence of depression, suicidality and associated risk factors among police officers in urban Tanzania.

Aims The aim of this study was to examine the prevalence of depression, suicidality and associated risk factors among police officers in Tanzania.

Methods A cross-sectional study was conducted between April 2019 and October 2020 among 550 participants in Dar es Salaam recruited using a multistage cluster sampling technique. The Patient Health Questionnaire-9 was used to screen for depression and suicidality. The Interpersonal Support Evaluation List-12 tool was used to measure perceived social support. Descriptive statistics were summarised using frequencies and percentages. Bivariate and multivariate analyses were used to establish associations between predictors of interest, depression and suicidality.

Results There were 497 participants in the study. Of these, $76.6 \%$ (376 of 491 ) were men, and the median (IQR) age was 37.0 (17) years. Around 19.8\% (96 of 486) of the police officers screened positive for depression and $15.4 \%$ (75 of 413 ) for suicidality. A significant proportion was either moderately ( 29 of $96,30.2 \%$ ) or severely depressed (8 of $75,10.7 \%$ ). Of those who experienced suicidal thoughts, $10.7 \%$ (8 of 75 ) reported having daily suicidal thoughts. Perceiving low social support was associated with an increased risk of reporting depression (adjusted OR (aOR): $28.04,95 \% \mathrm{Cl}: 8.42$ to $93.37, \mathrm{p}<0.001$ ) and suicidality (a0R: $10.85,95 \% \mathrm{Cl}: 3.56$ to $33.08, \mathrm{p}<0.001$ ) as compared with those with high perceived social support. Conclusion The magnitude of depression and suicidality among police officers in urban Tanzania is alarmingly high. The study findings indicate the need for routine screening for depression and suicidality among police officers and design appropriate mental health responsive services in this population.

\section{INTRODUCTION}

Mental health problems play an important role in the non-communicable disease burden, and are estimated to affect about 300 million people globally. ${ }^{1}$ According to the WHO report, major depressive disorder was estimated to be the second leading cause of the global burden of disease by $2020 .^{2}$ The prevalence of depression in the global population ranges from $1.9 \%$ to $19 \%$, ranked globally as the most significant contributor to non-fatal health $\operatorname{loss}^{2-4}$; while the prevalence of suicidal ideation ranges from $3.3 \%$ to $13.5 \% .{ }^{5}$ In Africa, the prevalence of depression in the general population was reported to be at between $9 \%$ and $11.6 \%$, of which $95 \%$ of the cases were in sub-Saharan Africa (SSA). ${ }^{2}$ The prevalence of depression in the general popoulation of Tanzania is $4.1 \%$, while suicide has been reported in 2.3/100 000 of the general population. ${ }^{7-9}$

Studies have reported the prevalence of depression at $10.6 \%-14.6 \%$ among police officers. ${ }^{810}$ Multifactorial causes such as workrelated exposure and traumatic events place first crisis responders and police officers at an increased risk of developing depression and suicide as compared with the general population. ${ }^{10-13}$ Suicidal ideation has been estimated to affect $8.5 \%(7.4 \%-25 \%)$ of police officers globally, which is twice as high as the magnitude reported in the general population. ${ }^{101415}$ Suicidality can be a direct result of exposure to trauma, but most studies have linked suicidality in police officers with preceded post-traumatic stress disorder (PTSD) symptomatology, alcohol abuse and depression. $^{13}$

Social and organisational stressors such as lack of organisational support and rewards, heavy workload and non-standard work hours were shown to be significant predictors of mental health problems compared with operational stressors including exposure to traumatic events and violence. ${ }^{16-18}$ Sociodemographic factors such as age, gender, education, marital status, and length of exposure to police work as well as social support have been linked to depression and suicidality. ${ }^{19-21}$ 
There is paucity of data on the magnitude and factors associated with depression and suicidality among police officers in Tanzania. Therefore, the aim of the study was to examine the prevalence of depression, suicidality and associated risk factors among police officers in Tanzania. The findings of this study will help to strengthen mental health promotion, prevention and treatment services in this particular population.

\section{METHODS}

\section{Study aim, design and setting}

This study aimed to determine the prevalence of depression, suicidality and associated risk factors among police officers in urban Tanzania. We conducted a communitybased cross-sectional survey in Dar es Salaam region, Tanzania from April 2019 to October 2020.

\section{Study participants}

We included the police officers who were residing in Dar es Salaam and were available at their respective police stations at the time of study. Retired police officers and those who were absent at the respective police stations during the study period were excluded. No age restriction was considered during the enrolment.

\section{Sample size determination and technique}

Multistage cluster sampling involving three stages was used to obtain the sampled police officers. Multistage cluster sampling is useful in obtaining participants in a complex population. ${ }^{22}$ In the first stage, all three clusters of police regions (Kinondoni, Temeke and Ilala) in Dar es Salaam City were selected. The second stage involved random selection of two district police units from the three sampled police regions. In the last stage, a convenient secondary sample of individual participants was obtained. A sample of 497 police officers was calculated using the proportional formula for calculating sample size (Kish and Leslie formula), the prevalence of depression of $10.6 \%$ and $5 \%$ standard error (SE) were used for calculation. $^{8}$

\section{Data collection process and instruments}

Data collection was conducted by trained research assistants in cooperation with some of the co-authors. We visited two police districts in each police region and three special police units (field force unit, police band, and information and communication technology unit). Data collection was done consecutively involving all the consented police officers available at the time of recruitment. Consented participants completed the semistructured self-administered questionnaires for sociodemographics (age, gender, education, rank, years served in police force, promotion status, police section), social support and depression screeners.

Depression was assessed using the validated Patient Health Questionnaire-9 (PHQ-9) consisting of nine items. The reliability of PHQ-9 has been documented in our Tanzanian setting with a good reliability $(\alpha=0.83) .{ }^{23}$ The participants were required to choose if over the last 2 weeks, they had experienced the mentioned symptoms. The responses were either not at all (0), for several days (1), more than half the days (2) or nearly every day (3); depression was defined by a score of $>9$, shown to have a sensitivity of $78 \%$ and specificity of $87 \% .{ }^{23}$ Depression severity was obtained using a scale of 10-14, 15-19 or 20-27 as moderate, moderately severe or severe depression, respectively.

The ninth question in PHQ-9 measures suicidality. The participants were asked how often over the last 2 weeks they have been bothered by thoughts that they would be better off dead or hurting oneself in anyway. If the responses were either for several days, more than half the days or nearly every day, they were considered to have suicidality (suicidal ideation).

Perceived social support was measured by the short version of the Interpersonal Support Evaluation List consisting of 12 items. It has three different subscales designed to measure three dimensions of perceived social support namely appraisal, belonging and tangible supports. Each of these dimensions was measured by a 4-point scale ranging from definitely false (1) to definitely true (4); six questions were reverse scored. The tool has been previously validated with internal consistency (Cronbach's $\alpha: 0.452-0.752$ ) and test-retest reliability of $0.88-0.90$ in English and Hispanic communities ${ }^{24} 25$, but not in Tanzania. A score of 12-30, 31-41 or 42-48 was defined as low, fair or high social support, respectively. ${ }^{25}$

\section{Data analysis}

All data entry, cleaning and subsequent data analysis were completed using SPSS for Windows V.20. In data cleaning, we performed missing value analysis and identified out-of-range values by running frequency tests for each variable and did the amendments accordingly. Out of 550 enrolled participants, $497(90.4 \%)$ police officers who responded to at least one of the general sociodemographic questions were included in the initial analysis. In bivariate and multivariate analyses for depression, 486 participants of the initial 497 police officers were considered for analysis as they responded to at least five of the questions on the PHQ-9 depression tool. For suicidality, we included 413 participants who responded to the ninth item on the PHQ-9 that assessed suicidal ideation. Eighty-four participants did not respond to this item, hence they were excluded in the final suicide analysis.

In the bivariate and multivariate analyses, the ORs with corresponding $95 \%$ CI were used to determine associations between sociodemographic factors, perceived social support, depression and suicidality. All factors were included in the multivariate regression analysis regardless of their level of significance in bivariate regression and the statistical significance level was set at 0.05 . 
A total of 550 police officers met the criteria to be included in the study. Inclusion criteria:

— those working as police officers for five years or more;

- police officers residing in Dar es Salaam city at the time of study;

- police officers that were available at the police stations at the time of data collection.

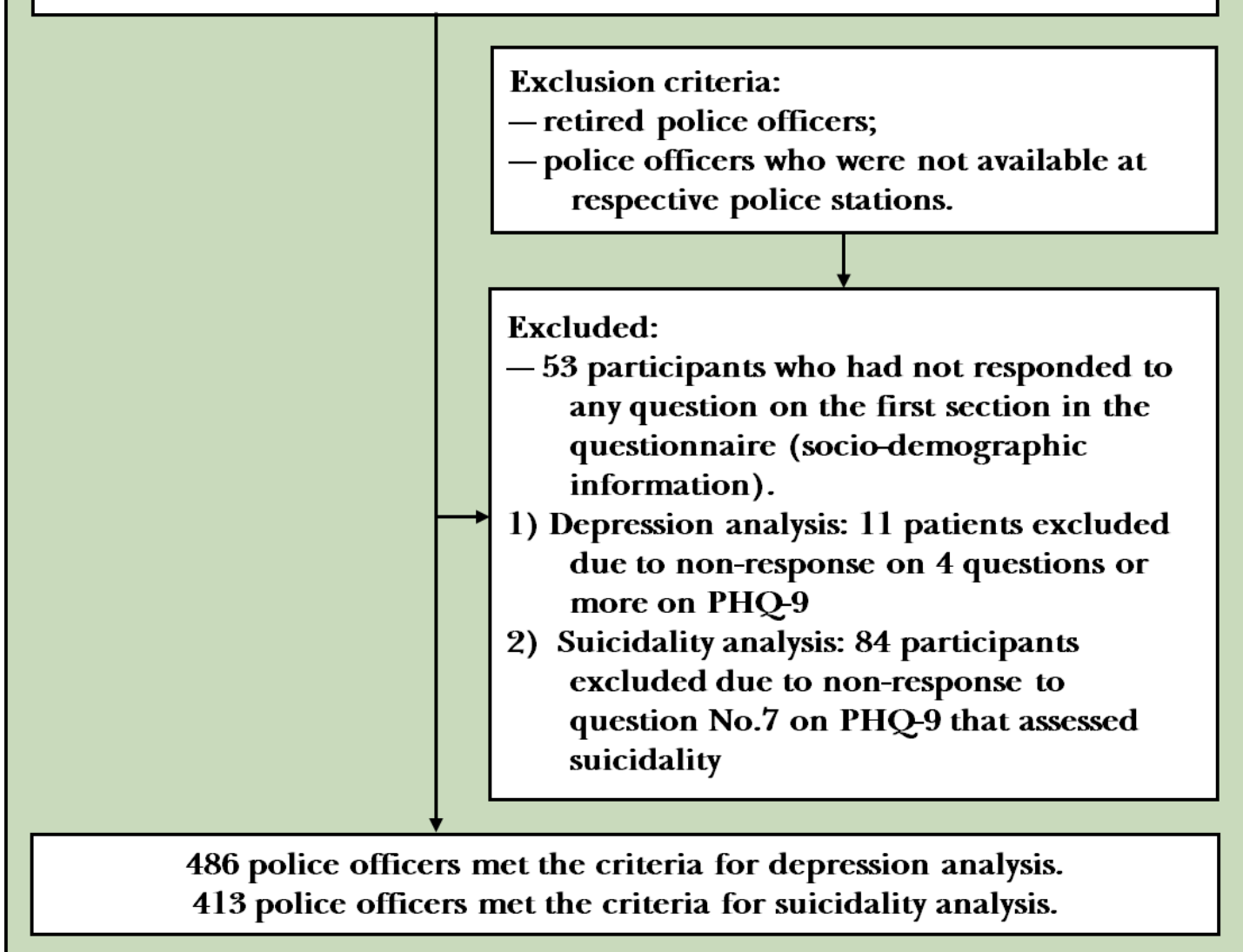

Figure 1 Study participants' enrolment flowchart. PHQ-9, Patient Health Questionnaire-9.

\section{RESULTS}

Demographic characteristics of study participants

We enrolled a total of 550 participants, with a response rate of $90.4 \%$ (497 of 550), the remainder had incomplete information in their questionnaires (figure 1). There were 53 participants excluded since they had not responded to any question on the first section in the questionnaire (sociodemographic information). In the depression analysis, 11 patients were excluded due to non-response on four questions or more on PHQ-9 questions, so there were 486 police officers in the final analysis. In the suicidality analysis, 84 participants were excluded, as they did not respond to question number 7 on the PHQ-9 that assessed suicidality, so there were 413 police officers in the final analysis. Among the 497 participants, the majority of the participants were men $(76.6 \%, 376$ of 491 ), and $38.1 \%$ of the participants were aged 41 years and above, with a median age (IQR) of the participants of 37.0 (17) years. About three-quarters $(76.3 \%, 371$ of 473 ) of the participants were married and just about half $(47.0 \%, 231$ of 491) of the participants reported having attained secondary education, and about half of the participants $(52.6 \%, 249$ of 473) reported to have been working in the police force for 5-14 years (table 1).

\section{Prevalence and predictors of depression among police} officers

The frequency and percentages of police officers who were screened for depression and sociodemographic variables are presented in table 2 . The prevalence of depression among police officers was found to be $19.8 \%$. Among participants who had depression, one-third $(30.2 \%)$ were found to have moderate to severe depression. Younger age group and those who served fewer years in police work were at an increased risk of depression. Multivariate logistic regression revealed that police officers with low perceived social support (adjusted OR (aOR): 28.04, 95\% CI: 8.42 to $93.37, \mathrm{p}<0.001$ ) were found to be at an increased risk of developing depression (table 2). Sex, marital status, rank at work, promotion status and police sections did not show any significant association with depression. 
Table 1 Sociodemographic characteristics of the study participants

\begin{tabular}{lll}
\hline Characteristic & N & $\begin{array}{l}\text { Percent } \\
\text { (\%) }\end{array}$ \\
\hline Sex $(n=491)$ & & \\
Male & 376 & 76.6 \\
Female & 115 & 23.4
\end{tabular}

Age groups $(\mathrm{n}=397)$

$\begin{array}{lll}21-30 & 105 & 26.4 \\ 31-40 & 141 & 35.5 \\ 41 \text { and above } & 151 & 38.1\end{array}$

Marital status $(n=473)$

\begin{tabular}{|c|c|c|}
\hline Single & 92 & 19.4 \\
\hline Married & 371 & 76.3 \\
\hline Separated and widowed & 20 & 4.3 \\
\hline \multicolumn{3}{|l|}{ Education $(n=491)$} \\
\hline Primary & 53 & 10.8 \\
\hline Secondary & 231 & 47 \\
\hline Higher education & 207 & 42.2 \\
\hline
\end{tabular}

Years served in police force $(n=473)$

\begin{tabular}{|c|c|c|}
\hline $5-14$ & 249 & 52.6 \\
\hline 15 and above & 224 & 47.4 \\
\hline \multicolumn{3}{|c|}{ Last year of promotion $(n=479)$} \\
\hline$<5$ years & 344 & 71.8 \\
\hline $5-10$ years & 97 & 20.3 \\
\hline$>10$ years & 38 & 7.9 \\
\hline \multicolumn{3}{|l|}{ Rank at work $(n=494)$} \\
\hline Gazette officer & 22 & 4.5 \\
\hline Inspector† & 60 & 12.1 \\
\hline Rank and fileł & 412 & 83.4 \\
\hline \multicolumn{3}{|l|}{ Police sections $(n=489)$} \\
\hline General duty & 130 & 26.6 \\
\hline Specialised sections§ & 359 & 73.4 \\
\hline \multicolumn{3}{|c|}{ Years served in police section $(n=474)$} \\
\hline 1 year and below & 45 & 9.5 \\
\hline More than a year & 114 & 24 \\
\hline More than 5 years & 315 & 66.5 \\
\hline \multicolumn{3}{|c|}{ Operational activities $(n=478)$} \\
\hline Yes & 355 & 74.3 \\
\hline No & 123 & 25.7 \\
\hline \multicolumn{3}{|c|}{ Perceived social support $(n=426)$} \\
\hline High & 163 & 38.3 \\
\hline Fair & 215 & 50.4 \\
\hline Low & 48 & 11.3 \\
\hline \multicolumn{3}{|l|}{ Police regions $(n=497)$} \\
\hline Ilala & 126 & 25.4 \\
\hline Kinondoni & 127 & 25.6 \\
\hline Temeke & 86 & 17.3 \\
\hline
\end{tabular}

Continued
Table 1 Continued

\begin{tabular}{lcc}
\hline Characteristic & N & $\begin{array}{l}\text { Percent } \\
\text { (\%) }\end{array}$ \\
\hline FFU & 76 & 15.3 \\
Police band & 44 & 8.9 \\
Main store & 38 & 7.6 \\
\hline
\end{tabular}

*Gazette officers (inspector general of police, commissioner of police (CP), deputy $\mathrm{CP}$, senior assistant $\mathrm{CP}$, assistant $\mathrm{CP}$, senior superintendent of police)

†Inspectors (superintendent of police (SP), assistant SP) †Rank and files (Regimental sergeant majors/sergeant majors, station sergeant, sergeant, corporal police and police constable) §Specialised sections (FFU, information and communication technology, medical unit, criminal investigation department, main police depot, traffic department, police band, police colleges, dogs and horse section, mechanical department, antidrugs unit, construction and building department) FFU, field force unit.

Prevalence and predictors of suicidality among police officers The prevalence of suicidal ideation among police officers was found to be $15.4 \%$ ( 75 of 413 ), of which $10.7 \%$ ( 8 of 75 ) of those who experienced suicidal ideation reported experiencing suicidal ideation nearly every day. Police officers who reported low perceived social support were at an increased risk of having suicidality (aOR: 10.85 , 95\% CI: 3.56 to $33.08, \mathrm{p}<0.001)$. Other factors did not show significant associations with suicidal ideation (table 3 ).

\section{DISCUSSION}

Main findings

The current study findings provide the prevalence of depression and suicidality among police officers in Dar es Salaam, Tanzania.

Police officers who served for 5-14 years in the police force and those with low perceived social support were at an increased risk of depression compared with their counterparts. Police officers with low perceived social support were at an increased risk of suicidality.

Our study found the prevalence of depression to be $19.8 \%$. This finding is consistent with a study done among police officers in Sri Lanka which reported a depression prevalence of $22.8 \%$ using a different research tool (Depression, Anxiety and Stress Scale) with reported correlation of 0.87 with $\mathrm{PHQ}-9^{8}{ }^{26}$, this could also be attributed by the two studies being conducted in middle-income countries. However, findings from a study done by Lawson et al revealed significantly higher levels of depression among Australian police officers $(65.4 \%)$ which can be attributed to the use of a different research tool (Center for Epidemiologic Studies Depression tool) and sociocultural differences between these two study sites. ${ }^{27}$

Our study found relatively higher levels of depression among this subpopulation compared with studies done among the general population in SSA. ${ }^{28}{ }^{29}$ The nature of police work has been found to explain this 
Table 2 Bivariate and multivariate analyses of factors associated with depression among police officers in Dar es Salaam

\begin{tabular}{|c|c|c|c|c|}
\hline Characteristics/variables & Depression (n, \%) & cOR $(95 \% \mathrm{Cl})$ & $P$ value & aOR (95\% Cl) \\
\hline \multicolumn{5}{|l|}{$\operatorname{Sex}(n=481)$} \\
\hline Male & $74(20.1)$ & 1 & 0.882 & 1 \\
\hline \multicolumn{5}{|l|}{ Age groups $(n=388)$} \\
\hline $21-30$ & $27(26.2)$ & $2.002(1.07 \text { to } 3.764)^{*}$ & 0.031 & 1 \\
\hline 41 and above & $22(15.1)$ & 1 & & $0.68(0.17$ to 2.71$)$ \\
\hline \multicolumn{5}{|l|}{ Marital status $(n=464)$} \\
\hline Single & $19(21.3)$ & 0.81 (0.26 to 2.53$)$ & 0.722 & 1 \\
\hline Married & $72(20.3)$ & $0.76(0.27$ to 2.17$)$ & 0.612 & 1.45 (0.58 to 3.66$)$ \\
\hline Others & $5(25.0)$ & 1 & & $0.92(0.15$ to 5.74$)$ \\
\hline Higher education & $46(22.4)$ & 2.604 (0.98 to 6.94) & 0.056 & 6.34 (0.65 to 61.83$)$ \\
\hline \multicolumn{5}{|l|}{ Ranks $(n=484)$} \\
\hline Officers & $2(9.1)$ & 0.37 (0.08 to 1.60$)$ & 0.183 & 1 \\
\hline Inspectors & $8(13.3)$ & 0.57 (0.26 to 1.24$)$ & 0.153 & 1.18 (0.19 to 7.24$)$ \\
\hline File & $86(21.4)$ & 1 & & $1.11(0.18$ to 6.80$)$ \\
\hline \multicolumn{5}{|l|}{ Years at work $(n=464)$} \\
\hline $5-14$ & $60(24.5)$ & $1.83(1.14$ to 2.93$)$ & 0.012 & 1 \\
\hline 15 and above & $33(15.1)$ & 1 & & $0.59(0.19$ to 1.81$)$ \\
\hline \multicolumn{5}{|l|}{ Operational activities $(n=470)$} \\
\hline No & $27(22.7)$ & 1 & & $0.68(0.29$ to 1.57$)$ \\
\hline \multicolumn{5}{|l|}{ Police section $(n=456)$} \\
\hline General duty & $21(16.7)$ & 0.74 (0.44 to 1.27$)$ & 0.277 & 1 \\
\hline Specialised sections & $75(21.2)$ & 1 & & 0.93 (0.39 to 2.15$)$ \\
\hline \multicolumn{5}{|c|}{ Perceived social support $(n=426)$} \\
\hline High & $11(6.8)$ & 1 & & 1 \\
\hline Fair & $45(20.9)$ & 3.63 (1.81 to 7.28$)$ & $<0.001$ & 4.56 (1.97 to 10.59$)$ \\
\hline Low & $26(55.3)$ & 16.99 (7.34 to 39.36$)$ & $<0.001$ & 28.04 (8.42 to 93.37$)$ \\
\hline
\end{tabular}

${ }^{*}$ Factors that were statistically significant $(p<0.05)$.

aOR, adjusted OR; cOR, crude OR.

difference. First-line crisis responders were shown to have higher levels of depression and PTSD as a result of dealing with violent acts, death and abuse during work duties which can be psychologically stressful. ${ }^{30}$

About $15.0 \%$ of police officers in our study reported having suicidality. This prevalence is higher than that reported in South Africa $(8.64 \%-10.58 \%){ }^{31} 32$ However, studies done in developed countries demonstrated higher levels of suicidality (such as $23.1 \%-25 \%$ in the $\mathrm{USA}^{33}$ ) compared with the present studies in developing countries. The differences in rates between developed and developing countries warrant further investigations. ${ }^{143435}$ Police officers' exposure to traumatic incidences and violence predisposes them to PTSD and substance use as a coping mechanism, which increased risk of suicidality. ${ }^{13} 33$

Studies have reported suicide ideation to be the most significant predictor that placed police officers 
Table 3 Bivariate and multivariate analyses of factors associated with suicidality among police officers in Dar es Salaam

\begin{tabular}{|c|c|c|c|c|}
\hline Characteristics/variables & Suicidality (n, \%) & cOR $(95 \% \mathrm{Cl})$ & $P$ value & aOR (95\% Cl) \\
\hline \multicolumn{5}{|l|}{$\operatorname{Sex}(n=483)$} \\
\hline Male & $58(15.7)$ & 1.05 (0.58 to 1.89$)$ & 0.871 & 1 \\
\hline Female & $17(15.0)$ & 1 & & 1.21 (0.52 to 2.82$)$ \\
\hline \multicolumn{5}{|l|}{ Age group $(n=390)$} \\
\hline $21-30$ & $16(15.5)$ & $1.11(0.55$ to 2.25$)$ & 0.768 & 1 \\
\hline $31-40$ & $22(15.8)$ & 1.14 (0.59 to 2.18$)$ & 0.768 & 0.62 (0.23 to 1.67$)$ \\
\hline 41 and above & $21(14.2)$ & 1 & & 0.34 (0.08 to 1.39$)$ \\
\hline \multicolumn{5}{|l|}{ Marital status $(n=466)$} \\
\hline Single & $13(14.6)$ & 0.68 (0.19 to 2.37$)$ & 0.55 & 1 \\
\hline Married & $58(16.2)$ & $0.78(0.25$ to 2.41$)$ & 0.66 & $1.21(0.44$ to 3.34$)$ \\
\hline Others & $4(20.0)$ & 1 & & 1.17 (0.19 to 6.92$)$ \\
\hline \multicolumn{5}{|l|}{ Education $(n=483)$} \\
\hline Primary education & $6(11.8)$ & $0.73(0.29$ to 1.84$)$ & 0.499 & 1 \\
\hline Secondary education & $37(16.4)$ & $1.06(0.64$ to 1.78$)$ & 0.812 & 1.33 (0.23 to 7.95$)$ \\
\hline Higher education & $32(15.5)$ & 1 & & $1.42(0.23$ to 8.66$)$ \\
\hline \multicolumn{5}{|l|}{ Police rank ( $n=486)$} \\
\hline Officers & $2(9.1)$ & $0.53(0.12$ to 2.33$)$ & 0.402 & 1 \\
\hline Inspectors & $9(15.0)$ & $0.94(0.44$ to 1.99$)$ & 0.867 & 2.18 (0.23 to 20.86$)$ \\
\hline File & $64(15.8)$ & 1 & & $1.28(0.13$ to 12.51$)$ \\
\hline \multicolumn{5}{|l|}{ Years at work $(n=465)$} \\
\hline $5-14$ & $41(16.7)$ & $1.27(0.76$ to 2.12$)$ & 0.354 & 1 \\
\hline 15 and above & $30(13.6)$ & 1 & & 1.60 (0.53 to 4.83$)$ \\
\hline \multicolumn{5}{|l|}{ Years last promoted $(n=469)$} \\
\hline Less than 5 years & $76(21.2)$ & 0.80 (0.34 to 1.92$)$ & 0.622 & 1 \\
\hline $5-10$ years & $11(15.1)$ & $0.38(0.12$ to 1.24$)$ & 0.109 & 1.04 (0.31 to 3.45$)$ \\
\hline More than 10 years & 7 (18.9) & 1 & & 2.29 (0.67 to 7.89$)$ \\
\hline \multicolumn{5}{|l|}{ Operational activities $(n=471)$} \\
\hline Yes & $54(15.4)$ & 1.10 (0.61 to 1.99$)$ & 0.748 & 1 \\
\hline No & $17(14.2)$ & 1 & & $0.52(0.20$ to 1.35$)$ \\
\hline \multicolumn{5}{|l|}{ Police section $(n=456)$} \\
\hline General duty & $14(11.0)$ & $0.59(0.32$ to 1.11$)$ & 0.103 & 1 \\
\hline Specialised sections & $61(17.2)$ & 1 & & 1.09 (0.43 to 2.78$)$ \\
\hline \multicolumn{5}{|c|}{ Perceived social support $(n=426)$} \\
\hline High & $14(8.64)$ & 1 & & 1 \\
\hline Fair & $30(13.95)$ & 1.71 (0.88 to 3.35$)$ & 0.115 & $1.43(0.64$ to 3.19$)$ \\
\hline Low & $21(43.75)$ & 8.22 (3.73 to 18.13$)$ & $<0.001$ & 10.85 (3.56 to 33.08$)$ \\
\hline
\end{tabular}

aOR, adjusted OR; cOR, crude OR.

at increased risk of subsequent suicide behaviours. Suicide ideation measured by the PHQ-9 has been associated with increased risk of suicide attempt (up to 10 times higher) as compared with those who did not endorse suicide ideation. ${ }^{36}$ Daily suicidal ideation has been shown to increase the risk of dying by suicide by up to 11 times. ${ }^{37}$

This study found a higher level of education to be associated with depression. This finding is incongruent with findings from a study done by Wickramasinghe et al which found no association between level of education and depression among police officers in Sri Lanka. ${ }^{8}$ Educated police officers are likely to get higher ranks at work with increased work demands and requirements which again predispose them to more psychological stress. ${ }^{38}$

Inconsistent with our findings, several studies conducted globally had shown that those who served longer in the police force were at an increased risk of developing depression. Long exposure to organisational 
and operational stressors at work has been found to significantly predict the level of depression in studies done among police workers in China and Italy. ${ }^{152}$ However, the earlier period of working may be a primary stressor for those who had served for fewer years and with time police officers may have developed some coping mechanisms that mask most depressive symptoms for those who served longer. Therefore, there may be a need for periodical mental check-ups and offering interventions directed towards police officers at different times in their career.

Similar to our findings, a study done by Broadhead et al had found that police officers who reported having low social support were twice as likely to develop depression. ${ }^{39}$ A review article conducted on suicide among police officers reported family-social support to be a protective factor among first responders. Social support and acknowledgement at work were reported as protective factors against occupational stress and mental health problems as they provide a buffering effect for possible stressful situations experienced at the workplace. ${ }^{30} 3334$ Therefore, social and psychological interventions directed towards this population may alleviate the effect brought about by stressful work experiences.

\section{Limitations}

The use of self-administered questionnaires in data collection led to a significant number of missing data due to incomplete responses. However, this method was preferred to the interview method as it allowed for greater transparency and privacy in sharing personal information.

Another issue was that the participants providing socially desirable answers from fear of being pointed out as abnormal would increase the challenges in getting a real picture regarding the participant's mental condition. In addition, this study included a relatively large sample size, but the findings may not be generalisable to all police officers in Tanzania since the study was conducted in an urban setting where police operations and organisational factors may be different from rural settings.

\section{Implications}

The magnitude of depression and suicidality among police officers in urban Tanzania is concerning. Higher education level and low perceived social support were found to be associated with depression among police officers. Low perceived social support was found to be the only independent predictor for suicidality. Our study underscores the urgent need to address depression and suicidality among police officers. Mental health awareness education, screening of mental health symptoms including depression and suicidality, and offering early intervention mental health services are required in the police force in Tanzania.

Acknowledgements The authors would like to acknowledge Dr Pamela Kaduri for her assistance in language editing.

Contributors BJN and HPN were involved in conceptualisation, proposal development, data collection, data analysis, interpretation and manuscript drafting.
SL and TK participated in conceptualisation, proposal development, data analysis and interpretation, and manuscript revision. EM, JM and $\mathrm{HC}$ participated in data collection and revised the manuscript. CJM and OU revised the manuscript. All authors read and approved the final version of this manuscript.

Funding The authors have not declared a specific grant for this research from any funding agency in the public, commercial or not-for-profit sectors.

Competing interests None declared.

Patient consent for publication Not required.

Ethics approval Muhimbili University of Health and Allied Sciences Ethical Review Board granted ethical approval of the study. The respective local authorities such as the inspector general of police (IGP) and the respective heads of police units in the police regions and districts from which the study samples were obtained within Dar es Salaam special zone allowed the researchers to conduct the study. Assent to participate in the study was sought from the eligible study candidates using written consent forms.

Provenance and peer review Not commissioned; externally peer reviewed.

Data availability statement Data set will be made available upon reasonable request.

Open access This is an open access article distributed in accordance with the Creative Commons Attribution Non Commercial (CC BY-NC 4.0) license, which permits others to distribute, remix, adapt, build upon this work non-commercially, and license their derivative works on different terms, provided the original work is properly cited, appropriate credit is given, any changes made indicated, and the use is non-commercial. See: http://creativecommons.org/licenses/by-nc/4.0/.

ORCID iD

Belinda Jackson Njiro http://orcid.org/0000-0002-8312-0643

\section{REFERENCES}

1 Metrics GH. Global, regional, and national incidence, prevalence, and years lived with disability for 354 diseases and injuries for 195 countries and territories, $1990-2017$ : a systematic analysis for the Global Burden of Disease Study 2017 2019:1990-2017.

2 WHO. Depression and other common mental disorders: global health estimates. Geneva: World Health Organization, 2017.

3 Bromet E, Andrade LH, Hwang I, et al. Cross-National epidemiology of DSM-IV major depressive episode. BMC Med 2011:9:90.

4 Fox J, Desai MM, Britten K, et al. Mental-Health conditions, barriers to care, and productivity loss among officers in an urban police department. Conn Med 2012;76:525-31.

5 Kessler RC, Bromet EJ. The epidemiology of depression across cultures. Annu Rev Public Health 2013;34:119-38.

6 Nock MK, Kessler RC. Prevalence of and risk factors for suicide attempts versus suicide gestures: analysis of the National comorbidity survey. J Abnorm Psychol 2006;115:616-23.

7 Mgaya E, Kazaura MR, Outwater A, et al. Suicide in the Dar ES Salaam region, Tanzania, 2005. J Forensic Leg Med 2008;15:172-6.

8 Wickramasinghe ND, Wijesinghe PR, Dharmaratne SD, et al. The prevalence and associated factors of depression in policing: a cross sectional study in Sri Lanka. Springerplus 2016;5:1776.

9 Wang Z, Inslicht SS, Metzler TJ, et al. A prospective study of predictors of depression symptoms in police. Psychiatry Res 2010;175:211-6.

10 Andersen J, Papazoglou K. Police health professionals' knowledge and practices in educating officers about trauma and health. Journal of Law Enforcement 2016;5:1-21.

11 Syed S, Ashwick R, Schlosser M, et al. Global prevalence and risk factors for mental health problems in police personnel: a systematic review and meta-analysis. Occup Environ Med 2020;77:737-47.

12 Netterstrøm B, Conrad N, Bech P, et al. The relation between workrelated psychosocial factors and the development of depression. Epidemiol Rev 2008;30:118-32.

13 Chae MH, Boyle DJ. Police suicide: prevalence, risk, and protective factors. Policing 2013;36:91-118.

14 Meyer R, Rothmann S, Pienaar J. Coping, stress and suicide ideation in the South African police service in the eastern Cape. South African Journal of Economic and Management Sciences 2005;6:881-904.

15 Violanti JM, Fekedulegn D, Charles LE, et al. Suicide in police work: exploring potential contributing influences. American Journal of Criminal Justice 2009;34:41-53.

16 Purba A, Demou E. The relationship between organisational stressors and mental wellbeing within police officers: a systematic review. BMC Public Health 2019;19:1-21. 
17 Hegarty S, Hyland P, Fitzgerald G, et al. Identifying the Key Risk Factors for Adverse Psychological Outcomes Among Police officers : A Systematic Literature Review 2019:688-700.

18 Jenkins R, Mbatia J, Singleton N, et al. Common mental disorders and risk factors in urban Tanzania. Int $J$ Environ Res Public Health 2010;7:2543-58.

19 Cohen S, Wills TA. Stress, social support, and the buffering hypothesis. Psychol Bull 1985;98:310-57.

20 Stress W. Police mental health : A Discussion paper October 2018 2018:1-14.

21 Warren TA. The Effects of Frequent Exposure to Violence and Trauma on Police Officers (2015). Walden Dissertations and Doctoral Studies. 1329. Available: https://scholarworks.waldenu.edu/dissertations/ 1329

22 Sedgwick P. Multistage sampling. BMJ $2015 ; ; 351$

23 Fawzi MCS, Ngakongwa F, Liu Y, et al. Screening of depression in Tanzania 2020:9-14.

24 Cohen S, Mermelstein R, Kamarck T. Measuring the Functional Components of Social Support. In: Sarason IG, Sarason BR, eds. Social support: theory, research and applications. NATO ASI series (D: behavioural and social sciences). 24. Dordrecht: Springer, 1985.

25 Merz EL, Roesch SC, Malcarne VL, et al. Validation of interpersonal support evaluation list-12 (ISEL-12) scores among Englishand Spanish-speaking Hispanics/Latinos from the HCHS/SOL sociocultural ancillary study. Psychol Assess 2014;26:384-94.

26 Ramsden K, Waechter S. DASS 21 or PHQ 9 for depression monitoring in routine clinical practice? 2019:1-5.

27 Lawson KJ, Rodwell JJ, Noblet AJ. Mental health of a police force: estimating prevalence of work-related depression in Australia without a direct national measure. Psychol Rep 2012;110:743-52.

28 Moledina SM, Bhimji KM, Manji KP. Prevalence and associated factors of depression in an Asian community in Dar ES Salaam, Tanzania. Psychiatry J 2018;2018:1-5.
29 Amoran O, Lawoyin T, Lasebikan V. Prevalence of depression among adults in Oyo state, Nigeria: a comparative study of rural and urban communities. Aust J Rural Health 2007;15:211-5.

30 Darensburg T, Andrew ME, Hartley TA, et al. Gender and age differences in posttraumatic stress disorder and depression among buffalo police officers. Traumatology 2006;12:220-8.

31 Swanepoel C, Pienaar J. "Coping, stress and suicide ideation in the South African Police Service in Gauteng Province.". Acta Criminologica: Southern African Journal of Criminology 2002;17:17-33.

32 Pienaar J, Rothmann S. Occupational stress in the South African police service. SA Journal of Industrial Psychology 2006;32.

33 Stanley IH, Hom MA, Joiner TE. A systematic review of suicidal thoughts and behaviors among police officers, firefighters, EMTs, and paramedics. Clin Psychol Rev 2016;44:25-44.

34 Steel Z, Marnane C, Iranpour C, et al. The global prevalence of common mental disorders: a systematic review and meta-analysis 1980-2013. Int J Epidemiol 2014;43:476-93.

35 Virginia W, Hartley TA, Virginia W, et al. Hhs public access 2015; 14:157-62.

36 Rutter CM, Ph D, Oliver M. Does response on the PHQ-9 depression questionnaire predict subsequent suicide attempt or suicide death? Psychiatr Serv 2013;64:1195-202.

37 Rossom RC, Coleman KJ, Ahmedani BK, et al. Suicidal ideation reported on the PHQ9 and risk of suicidal behavior across age groups. J Affect Disord 2017;215:77-84.

38 Jamison DT, Summers LH, Alleyne G, et al. Global health 2035: a world converging within a generation. Lancet 2013;382:1898-955.

39 Broadhead J, Abas M, Sakutukwa GK, et al. Social support and life events as risk factors for depression amongst women in an urban setting in Zimbabwe. Soc Psychiatry Psychiatr Epidemiol 2001;36:115-22.

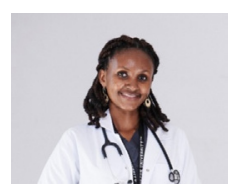

Dr. Belinda Jackson Njiro obtained her first degree (Doctor of Medicine) and graduated from Muhimbili University of Health and Allied Sciences in United Republic of Tanzania on December 2020. She is currently developing her clinical practice and working as an intern attending doctor at Internal Medicine Department of Muhimbili National Hospital in Tanzania, which was started in December 2020. She has been privileged to co-author 3 research activities related to communicable diseases including two SARS-CoV-2 studies in 2020 and one study on multi-drug resistance Tuberculosis in Tanzania. In addition, she has also been involved in public health activities. She is currently working in Sickle Cell Programme as a clinical research collaborator under Sickle Cell Kidney Project where she takes part in the ongoing research activities relating to sickle cell disease and the rapidly growing advanced therapy. Her main research interests include non-communicable diseases (mental health included), and the promotion, prevention and treatment of mental health problems and hence reduction of the burden of non-communicable diseases in Tanzania. 